\title{
LAMOTRIGINE (LAMICTAL) IN INTRACTABLE EPILEPSIES
}

The efficacy of lamotrigine (LTG) in an open, add-on, prospective study of 56 children with refractory generalized epilepsies is reported from British Columbia's Children's Hospital, Vancouver, BC, Canada. More than half had a greater than $50 \%$ reduction in seizure frequency, six children being seizurefree. Of 15 with Lennox-Gastaut syndrome, 3 were completely controlled and 8 had $>50 \%$ improvement. Skin rash and an increase in seizure frequency were the most frequent side effects, occurring in 5 and 7 children, respectively. Patients receiving valproate in combination with LTG were most likely to develop rash. LTG was reintroduced alone without recurrence of rash. (Farrell K, Connolly MB, Munn R, Peng S, MacWilliam LM. Prospective, open-label, addon study of lamotrigine in 56 children with intractable generalized epilepsy. Pediatr Neurol April 1997;16:201-205). (Respond: Dr Farrell, Division of Neurology, Dept Pediatrics, University of British Columbia, 4480 Oak St, Vancouver, BC, Canada V6H 3V4).

COMMENT. Lamotrigine may be of benefit in children with generalized seizures, including Lennox-Gastaut syndrome. Skin rash may be expected in $10 \%$, especially those receiving higher initial doses of LMG and valproate in combination. The reintroduction of an antiepileptic drug after occurrence of a skin rash is generally contraindicated and potentially hazardous. The present and two previous reports of successful reintroduction of LTG after skin rash are exceptions to the rule. Mimms J et al, Minnesota Epilepsy Group, St Paul, $\mathrm{MN}$, report one of 13 children treated with high dose lamotrigine having an allergic rash at 6 weeks, and a recurrence of rash after reintroduction of LTG (I Child Neurol Jan 1997;12:64-67).

Vigabatrin in partial seizures in children decreased seizure frequency by $>50 \%$ in $70 \%$ of patients, and was particularly effective in infants with tuberous sclerosis, in a study at Hopital Saint Vincent de Paul, Paris, France. (Nabbout RC, Chiron C et al. IChild Neurol April 1997;12:172-177).

\section{SEASONAL ONSET CHANGES IN INFANTILE SPASMS}

The influence of calendar month, day length (photoperiod), and globar solar radiation (GSR) on onset of infantile spasms was reviewed retrospectively using records of 76 infants at the Ilospital for Sick Children, University of Toronto, Ontario, Canada. Onset frequency increased as days were shorter, with a 2.2-fold higher frequency in December/January, months with a short photoperiod and low GSR, compared to June/July. Environmental photoperiodic factors (zeitgebers) may have a role in onset of infantile spasms. (Cortez MA, Burnham WM, IIwang PA. Infantile spasms: seasonal onset differences and zeitgebers. Pediatr Neurol April 1997;16:22()-224). (Respond: Dr Cortez, Division of Neurology, Ilospital for Sick Children, 555 University Ave, Toronto, Ontario, M5G 1X8, Canada).

COMMENT. The frequency of infantile spasm onset is highest in the fall and winter, during months with low globar solar radiation and short photoperiods. Possible causal factors suggested include seasonal variations in seizure threshold or ACTH release. Viral infections might also be a seasonal etiology.

Several factors may modify the threshold to seizures in animals and man, and seasonal variations have received little attention. Boldrey EE and Millichap JG, in a laboratory study and report of barometric pressure and 
seizures (Proc Soc Exp Biol Med. 1966;123:968), refer to WF Petersen's extensive treatise concerning effects of weather on disease and the relation between meteorological disturbances and onset and severity of epilepsy (1934). Also, Tille D had observed a higher incidence of febrile convulsions related to cold weather fronts (1950).

\section{NON-BENIGN FAMILIAL NEONATAL CONVULSIONS}

An electroclinical pattern characteristic of benign familial neonatal convulsions is reported in two neonates with non-benign seizures treated at the Miami Children's Hospital, FL. Ten seizures recorded by continuous videoEEG telemetry began with generalized tonic posturing and diffuse attenuation of EEG activity. Bilateral clonic movements that followed were accompanied by repetitive sharp waves or spikes. None had a family history of seizures, and one patient followed for 5 years had speech delay, hypotonia, hyperreflexia, and autistic behavior. The cause of seizures was undetermined. (Alfonso I, Hahn JS, Papazian $O$ et al. Bilateral tonic-clonic epileptic seizures in nonbenign familial neonatal convulsions. Pediatr Neurol April 1997;16:249-251). (Respond: Dr Alfonso, Department of Neurology, 3200 SW 60th Court, Suite 302, Miami, FL $33155)$.

COMMENT. The electroclinical events thought to be characteristic of benign familial neonatal convulsions (BFNC) are nonspecific. BFNC is heterogeneous in clinical and EEG features and cannot be distinguished from benign infantile familial convulsions on the basis of clinical seizure patterns. (see Progress in Pediatric Neurology III, 1997;pp8-9).

Outcome of neonates with electrographically identified seizures was correlated with background EEG and number of independent seizure foci in a study of 53 neonates at Sydney Children's Hospital, Australia (Bye AME et al. Pediatr Neurol April 1997;16:225-231). A severely depressed EEG background in a neonate with seizures or at risk of seizures was correlated with mortality during the first month, and frequent neonatal independent seizure foci correlated with poor outcome at 1 year.

\section{HANDICAPS ASSOCIATED WITH EPILEPSY}

The prevalence and severity of handicaps in 217 children and adolescents with epilepsy were assessed at the University of Goteborg, Ostra Hospital, Sweden, using the World Health Organization International Classification of Impairments, Disabilities and Handicaps (ICIDH). Major additional disorders occurred in 113 (52\%), mental retardation (MR) in 106 and cerebral palsy (CP) in 48 children. Motor and sensory disabilities, involving locomotion, arm and hand function, were common even in children unaffected by CP or MR. Handicap, defined as a disadvantage, resulting from a disability or impairment, adversely affected physical independence and orientation, correlated with epilepsy duration and secondary generalization, and was relieved by epilepsy surgery. (Beckung E, Uvebrant P. Impairments, disabilities and handicaps in children and adolescents with epilepsy. Acta Paediatr March 1997;86:254-260). (Respond: Dr E Beckung, Department of Paediatrics, University of Goteborg, Ostra Hospital, S-41685 Goteborg, Sweden).

COMMENT. Children with epilepsy complicated by cerebral palsy or mental retardation are diagnosed and treated early for their associated disabilities and handicaps. Those with epilepsy unassociated with CP or MR 